\title{
GBEP
}

\section{Apreensão dos sentidos: aprimorando a proposta dos núcleos de significação}

Wanda Maria Junqueira de Aguiar

Sergio Ozella

Resumo

Pretende aprimorar uma proposta de análise dos sentidos presentes no discurso, já publicada em 2006 pelos mesmos autores. Na primeira parte, é destacada a importância do referencial teórico e metodológico, no caso o da Psicologia Sócio-Histórica, e suas implicações para a apreensão dos sentidos. Para isso, discute algumas categorias, como mediação, historicidade, sentido e significado. Na segunda parte, é retomada a proposta já feita dos núcleos de significação como meio de se apreender os sentidos, mas à luz de novas reflexões e teorizações. Para ilustrar a forma de proceder à análise, um novo exemplo é apresentado, sendo que, nesse processo, foi possível avançar tanto no que se refere aos procedimentos de análise de material discursivo quanto na teorização essencial a todo o processo.

Palavras-chave: sentidos; núcleos de significação; Psicologia Sócio-Histórica. 


\section{Abstract \\ The senses apprehension: improving the core of meaning proposal}

This article aims to improve a proposal for analysis of senses present in the speech, already published in 2006, by these same authors. In the first part it has been highlighted the importance of theoretical and methodological framework, in the case of Historical Social Psychology and its implications for the apprehension of the senses. For this we discussed some categories, for example, mediation, historicity, sense and meaning. In the second part we take the proposal already made of the "core of meaning" as a means of apprehending the senses, but in the light of new reflections and theorizing. To illustrate the form of carrying out the analysis, we bring a new example, being that, in this case, it was possible to move forward, both as regards procedures for discursive material analysis and in theorizing essential throughout the process.

Keywords: senses; core of meaning; Historical Social Psychology.

Para iniciarmos nossa discussão sobre a categoria sentido e suas implicações metodológicas, torna-se necessário inicialmente que se destaque, mesmo que brevemente, alguns aspectos teórico metodológicos desenvolvidos especialmente por Vigotski, como a importância de um método materialista dialético, as categorias linguagem e pensamento e as noções de significado e sentido.

Desde 1927, quando escreveu O significado histórico da crise da psicologia - uma investigação metodológica, Vigotski (1991) destaca a importância de um método que desse conta da complexidade do que entendia como objeto da psicologia, ou seja, o homem e suas funções psicológicas. Fica evidente que a psicologia seria impotente para superar as tarefas práticas que se lhe apresentavam se não contasse com uma infraestrutura lógico-metodológica própria. Revela-se, dessa forma, nas reflexões do autor, a necessidade de uma teoria que fizesse a mediação entre o método materialista histórico e os fenômenos psíquicos.

Assim, concordamos com Vigotski (1991a, p. 471) que a tarefa daqueles que pretendem aplicar o marxismo à ciência deve ser a de elaborar um método, "um sistema de procedimentos mediadores concretos de organização dos conhecimentos que podem ser aplicados precisamente à escala desta ciência". Método é aqui entendido, para além de sua função instrumental, como algo que nos permite penetrar no real, objetivando não só compreender a relação sujeito/objeto, mas a própria constituição 
do sujeito, produzindo um conhecimento que se aproxime do concreto, síntese de múltiplas determinações.

Sem a intenção de nos determos na análise dos aspectos que definem tal método, destacamos como decorrência da adoção dessa perspectiva metodológica a crítica radical das visões reducionistas, objetivistas e subjetivistas, ${ }^{1}$ a discussão sobre a relação aparência/essência, parte/todo, a importância da noção de historicidade, de processo e a noção de mediação. ${ }^{2}$

Desse modo, frisamos que nossa reflexão metodológica sobre a apreensão dos sentidos estará pautada em uma visão que tem no empírico seu ponto de partida, mas com a clareza de que é necessário irmos para além das aparências, não nos contentarmos com a descrição dos fatos, mas buscarmos a explicação do processo de constituição do objeto estudado, ou seja, estudá-lo em seu processo histórico. No entanto, ao nos referirmos aos pontos essenciais a serem considerados sobre o método, não podemos deixar de mencionar a impossibilidade de se construir um método alheio a uma concepção de homem. Assim, falamos de um homem constituído numa relação dialética com o social e com a história, o que o torna ao mesmo tempo único, singular e histórico. Este homem, constituído na e pela atividade, ao produzir sua forma humana de existência, revela - em todas as suas expressões - a historicidade social, a ideologia, as relações sociais e o modo de produção. Ao mesmo tempo, esse mesmo homem expressa a sua singularidade, o novo que é capaz de produzir, os significados sociais e os sentidos subjetivos.

Indivíduo e sociedade vivem numa relação em que se incluem e se excluem ao mesmo tempo. Quando afirmamos que se incluem, lembramos Vigotski (2001) quando afirma que o indivíduo é "quase o social"; para ele, não há invenções individuais no sentido estrito da palavra, em todas existe sempre alguma colaboração anônima. E, quando afirmamos que se excluem, se diferenciam, destacamos a singularidade do sujeito. Dessa forma, indivíduo e sociedade não mantêm uma relação isomórfica entre si, mas uma relação onde um constitui o outro. Concordamos quando Vigotski $(1991$, v. 3) afirma que o "processo de internalização" deveria ser chamado de "processo de revolução", pressupondo uma radical reestruturação da atividade psíquica neste movimento chamado de internalização.

\section{Destacando algumas categorias}

Ainda nos detendo na questão metodológica, vemos a necessidade de apresentarmos algumas categorias importantes para a perspectiva adotada. Iniciamos com uma breve discussão sobre a categoria mediação. O uso desta categoria nos permite romper as dicotomias interno/externo, objetivo/subjetivo, significado/sentido, assim como nos afastar das visões naturalizantes, baseadas numa concepção de homem fundada na

${ }^{1}$ Ver mais sobre esta questão em Vigotski (1991a).

${ }^{2}$ Ver mais sobre a questão em Vigotski (1994, cap. 5) e Rey (1999). existência de uma essência metafísica. Por outro lado, nos possibilita uma análise das determinações inseridas num processo dialético, portanto não causal, linear e imediato, mas no qual as determinações são entendidas como elementos constitutivos do sujeito, como mediações. 
A apreensão do homem, como nos lembra Vigotski (2001), se dará pela compreensão da gênese social do individual, "pela compreensão de como a singularidade se constrói na universalidade e ao mesmo tempo e do mesmo modo, como a universalidade se concretiza na singularidade, tendo a particularidade como mediação" (Oliveira, 2001, p. 1). Estamos entendendo, desse modo, que o homem, ser social e singular, síntese de múltiplas determinações, nas relações com o social (universal) constitui sua singularidade através das mediações sociais (particularidades/ circunstâncias específicas). ${ }^{3}$

Assim, ao falarmos em mediação, nos referimos, como afirma Severino (2002, p. 44), "a uma instância que relaciona objetos, processos ou situações entre si; a partir daí o conceito designará um elemento que viabiliza a realização de outro que, embora distinto dele, garante a sua efetivação, dando-lhe concretude". A categoria mediação não tem, portanto, a função de apenas ligar a singularidade e a universalidade, mas de ser o centro organizador objetivo dessa relação. Ao utilizarmos a categoria mediação possibilitamos a utilização, a intervenção de um elemento/processo em uma relação que antes era vista como direta, permitindo-nos pensar em objetos/processos ausentes até então. Logo, como já colocamos acima, subjetividade e objetividade, externo e interno, nessa perspectiva, não podem ser vistos numa relação dicotômica e imediata, mas como elementos que, apesar de diferentes, se constituem mutuamente, possibilitando a existência do outro numa relação de mediação. A utilização desta categoria, claro que articulada às outras que ainda serão explicitadas, nos permitirá compreender o sujeito como aquele que, na sua relação com o mundo revela, em todas as suas expressões, o social e o individual e que, portanto, só será compreendido sob o prisma da "unidade dos contrários", ou seja, a lei da contradição inerente aos fenômenos. Como nos lembra Meszáros (2006, p. 81), "Nenhum sistema filosófico pode ser monista sem dominar conceitualmente, de uma forma ou de outra, a complexa inter-relação dialética entre a mediação e a totalidade". Importante destacar que totalidade aqui, segundo o materialismo histórico-dialético, deve ser entendida "como um todo estruturado em curso de desenvolvimento humano e de auto-criação" (Kosik, 2002, p. 43) e que, portanto, nunca se refere a algo fixo, imutável. Para que esse raciocínio seja possível, é necessário termos em conta a noção de totalidade concreta, jamais de modo apriorístico, sempre em movimento, constituída na e pela atividade dos homens. A noção de totalidade implica uma articulação dialética em que a parte e o todo, o singular e o plural estão imbricados dialeticamente um no outro, não se confundem, mas não existem isoladamente, por isso não são apreendidos separadamente. Isso significa que o singular expressa dimensões do plural ou do todo que o constitui, assim como o todo articula dialeticamente todas as possibilidades das singularidades a partir das quais se produz.

Outra importante categoria constitutiva deste método é a historicidade. Tal categoria nos permite olhar para a realidade e pensá-la em movimento e, mais do que isso, apreender seu movimento. Ela é aqui
${ }^{3}$ Ver mais sobre tais questões em Lukács (1967). 
alçada a princípio fundamental deste pensamento metodológico, pelo seu potencial de dar conta da gênese e do processo de transformação dos objetos.

"O que é" deixa de ser a pergunta principal para dar lugar à questão de "como surgiu", "como se movimentou e se transformou". Consideramos muito interessante uma passagem de Lukács (1979, p. 79), na qual ressalta que a história não é um simples movimento, ou seja, não se trata de um movimento sem rumo, indeterminado, desgovernado, mas de um movimento determinado por relações de forças que se constituíram no decurso da existência de tal objeto, sem que isso signifique um determinismo histórico:

A historicidade implica não o simples movimento, mas também e sempre uma determinada direção na mudança, uma direção que se expressa em transformações qualitativas de determinados complexos, tanto em si quanto em relação com outros complexos. (Lukács, 1979, p. 79).

Nossa tarefa, portanto, é apreender as mediações sociais constitutivas do sujeito, saindo assim da aparência, do imediato, indo em busca do processo, do não dito, do sentido.

Colocadas essas questões metodológicas, indicamos como um tema preliminar para a discussão dos sentidos e significados a relação pensamento/linguagem.

Muitos autores têm debatido este tema, assim, faremos uma breve retomada de alguns pontos essenciais para a discussão em questão.

Retomando nossas reflexões sobre a constituição dialética do homem, podemos afirmar que o plano individual não constitui mera transposição do social. O individuo modifica o social; transforma o social em psicológico e assim cria a possibilidade do novo. Logo, podemos afirmar que a linguagem seria o instrumento fundamental neste processo de constituição do homem. "Os Signos, entendidos como instrumentos convencionais de natureza social, são os meios de contato com o mundo exterior e, também, do homem consigo mesmo e com a própria consciência" (Aguiar 2000, p. 129). ${ }^{4}$

Assim, os signos, instrumentos psicológicos, são constitutivos do pensamento não só para comunicação, mas como meio de atividade interna. A palavra, signo por excelência, representa o objeto na consciência. Podemos, desse modo, afirmar que os signos representam uma forma privilegiada de apreensão do ser, pensar e agir do sujeito.

Como afirma Vigotski (2001, p. 409), "o pensamento não se exprime na palavra, mas nela se realiza", podendo, muitas vezes, "o pensamento fracassar", não se realizando como palavra. Dessa forma, para que se possa compreender o pensamento, entendido aqui como sempre emocionado,

${ }^{4}$ Smolka (2004) discute mais profundamente a questão do signo no capítulo "Sentido e significação - sobre significação e sentido: uma contribuição à proposta de rede de significados". temos que analisar seu processo, que se expressa na palavra com significado, e, ao apreender o significado da palavra, vamos entendendo o movimento do pensamento.

Temos assim que a relação pensamento/linguagem não pode ser outra que não de uma relação de mediação, na qual ao mesmo tempo que um 
elemento não se confunde com o outro, não pode ser compreendido sem o outro, onde um constitui o outro.

O pensamento passa, portanto, por muitas transformações para ser expresso em palavras, de modo a concluir-se que a transição do pensamento para a palavra passa pelo significado e o sentido. Dessa forma, podemos afirmar que a compreensão da relação pensamento/ linguagem passa pela necessária compreensão das categorias significado e sentido. Assim, destacamos a necessidade da discussão das categorias significado e sentido.

Apesar de optarmos por iniciar pela discussão da categoria significado, faz-se necessário explicitar que essas duas categorias, apesar de serem diferentes, de não perderem sua singularidade (fato que nos leva a discutílas separadamente), não podem ser compreendidas descoladas uma da outra, pois uma não é sem a outra.

Segundo Vigotski (2001), o significado, no campo semântico, corresponde às relações que a palavra pode encerrar; já no campo psicológico, é uma generalização, um conceito.

Na verdade, o homem transforma a natureza e a si mesmo na atividade, e é fundamental que se entenda que este processo de produção cultural, social e pessoal tem como elemento constitutivo os significados. Dessa maneira, a atividade humana é sempre significada: o homem, no agir humano, realiza uma atividade externa e uma interna, e ambas as situações (divisão esta somente para fins didáticos) operam com os significados. Nessa perspectiva, Vigotski (2001) lembra que o que internalizamos não é o gesto como materialidade do movimento, mas a sua significação, a qual tem o poder de transformar o natural em cultural.

Os significados são, portanto, produções históricas e sociais. São eles que permitem a comunicação, a socialização de nossas experiências. Muito embora sejam mais estáveis, "dicionarizados", eles também se transformam no movimento histórico, momento em que sua natureza interior se modifica, alterando, consequentemente, a relação que mantêm com o pensamento, entendido como um processo.

Os significados referem-se, assim, aos conteúdos instituídos, mais fixos, compartilhados, que são apropriados pelos sujeitos, configurados a partir de suas próprias subjetividades.

Ao discutir significado e sentido, é preciso compreendê-los como sendo constituídos pela unidade contraditória do simbólico e do emocional. Dessa forma, na perspectiva de melhor compreender o sujeito, os significados constituem o ponto de partida: sabe-se que eles contêm mais do que aparentam e que, por meio de um trabalho de análise e interpretação, pode-se caminhar para as zonas mais instáveis, fluidas e profundas, ou seja, para as zonas de sentido. Afirma-se, assim, que o sentido é muito mais amplo que o significado, pois o primeiro constitui a articulação dos eventos psicológicos que o sujeito produz ante uma realidade. Como diz Rey (2003), o sentido subverte o significado, pois ele não se submete a uma lógica racional externa. O sentido refere-se a necessidades que, muitas vezes, ainda não se realizaram, mas que mobilizam o sujeito, constituem 
${ }^{5}$ Rey (2003) faz uma discussão aprofundada sobre a questão das emoções, necessidades e motivos. o seu ser, geram formas de colocá-lo na atividade. A categoria sentido destaca a singularidade historicamente construída.

Fica evidenciada, desse modo, a complexidade de tal categoria, fato que sem dúvida gera grande dificuldade nas formas de apreendê-la. No entanto, é este o caminho que nos propomos a seguir: apreender o processo constitutivo dos sentidos, bem como os elementos que engendram este processo. Queremos nos apropriar daquilo que diz respeito ao sujeito, daquilo que representa o novo, que, mesmo quando não colocado explicita ou intencionalmente, é expressão do sujeito, configurado pela sua unicidade histórica e social, revelação das suas possibilidades de criação.

O sentido coloca-se em um plano que se aproxima mais da subjetividade, que com mais precisão expressa o sujeito, a unidade de todos os processos cognitivos, afetivos e biológicos. Portanto, como afirmam Aguiar et al. (2009, p. 65), "falar de sentidos é falar de subjetividade, da dialética afetivo/cognitivo, é falar de um sujeito não diluído, de um sujeito histórico e singular ao mesmo tempo".

Subjetividade é aqui entendida como uma possibilidade humana de organizar experiências convertidas em sentidos. É uma dimensão da realidade que podemos denominar dimensão subjetiva da realidade objetiva. Temos assim a possibilidade de um processo específico, marcado por uma dinâmica em que os sentidos "constituem-se a partir de complexas reorganizações e arranjos, em que a vivência afetiva e cognitiva do sujeito, totalmente imbricadas [...], é acionada e mobilizada" (Aguiar et al., 2009, p. 63).

No entanto, dada a sua complexidade, afirmamos como nossa possibilidade nos aproximarmos de algumas zonas de sentido.

Concordamos com Rey (2003) ao afirmar que o pensamento é um processo psicológico não só por seu caráter cognitivo, mas por ser sentido subjetivo, pelas significações e emoções que nele articulam. ${ }^{5}$

Como afirma Heller (1986, p. 74), "não pode haver um rosto completamente desprovido de expressão". Segundo a autora, o sentir seja positiva ou negativamente - sempre significa estar implicado em algo, a implicação vai assim ser vista como um fator constitutivo e inerente do atuar e do pensar. As emoções não podem, assim, serem vistas como passivas, como epifenômenos. Em Teoria das emoções, Vigotski (2004, p. 16), citando Spinosa, destaca o aspecto fundamental e constitutivo dos afetos, "afetos são estados corporais que aumentam ou diminuem a capacidade do corpo para a ação, a favorecem ou limitam, assim como as idéias que se tem sobre estes estados".

Na perspectiva adotada, portanto, a separação entre pensamento e afeto jamais poderá ser feita, sob o risco de fechar-se definitivamente o caminho para a explicação das causas do próprio pensamento, pois a análise do pensamento pressupõe necessariamente a revelação dos motivos, necessidades e interesses que orientam o seu movimento. Desse modo, além de apontarmos a relação dialética entre o aspecto afetivo e o simbólico, destacamos a importância de agregarmos a noção de necessidade e os motivos para a compreensão do sujeito e, assim, 
dos sentidos. Concordamos com Aguiar et al. (2009) ao afirmarem que tais categorias são fundamentais na tarefa de apreensão dos sentidos, nos permitindo a criação de zonas de inteligibilidade no processo de constituição dos sentidos. A seguir, apresentamos as categorias necessidades e motivos.

As necessidades estão sendo entendidas como um estado de carência do indivíduo que leva a sua ativação com vista a sua satisfação, dependendo das suas condições de existência. Temos, assim, que as necessidades se constituem e se revelam a partir de um processo de configuração das relações sociais, processo este que é único, singular, subjetivo e histórico ao mesmo tempo. Além disso, é fundamental ressaltar que, pelas características do processo de configuração, o sujeito não necessariamente tem o controle e muitas vezes a consciência do movimento de constituição das suas necessidades. Assim, tal processo só pode ser entendido como fruto de um tipo específico de registro cognitivo e emocional, ou seja, a constituição das necessidades se dá de forma não intencional, tendo nas emoções um componente fundamental. Pode-se dizer que tais registros constitutivos das necessidades não necessariamente são provenientes das significações, podendo se constituir em afecções que ainda não foram significadas. Como coloca Rey (2003, p. 245), "se a emoção diz não, os meios não estão disponíveis [...], a emoção é que define a disponibilidade dos recursos subjetivos do sujeito para atuar".

Evidencia-se, desse modo, a complexidade desse processo, marcado especialmente pela força dos registros emocionais geradores de um estado de desejo, de tensão, que mobiliza o sujeito, que cria experiências afetivas e que, como atividade psíquica, tem papel regulador.

Este estado emocional que mobiliza deve ser analisado para chegarmos aos sentidos. Mas ainda falta um elo. Estas necessidades vividas como estado dinâmico ainda não dão uma direção ao comportamento. Este processo de ação do sujeito no mundo a partir das suas necessidades só vai se completar quando o sujeito significar algo do mundo social como possível de satisfazer suas necessidades. Ai sim, este objeto/fato/pessoa vai ser vivido como algo que impulsiona/direciona, que motiva o sujeito para ação na direção da satisfação das suas necessidades. Tal movimento, ou seja, a possibilidade de realizar uma atividade que vá na direção da satisfação das necessidades, com certeza modifica o sujeito, criando novas necessidades e novas formas de atividade. Afirmamos, assim, que a necessidade completa sua função quando "descobre" na realidade social o objeto que poderá satisfazê-la. Entendemos que esse movimento se define como a configuração das necessidades em motivos. Com isso estamos dizendo que os motivos se constituirão como tal somente no encontro com o sujeito, no momento que o sujeito o configurar como possível de satisfazer as suas necessidades.

Ao se apreender o processo por meio do qual os motivos se configuram, avança-se na apropriação do processo de constituição dos sentidos, definidos como a melhor síntese do racional e do emocional. Aproximamo-nos, dessa forma, do processo gerador da atividade, ao 
mesmo tempo gerado por ela. Apreendemos o que é a atividade para o sujeito e assim algumas zonas de sentidos da atividade, claro que atravessadas pelos significados, mas, no caso, revelando uma forma singular de vivê-las e articulá-las.

A apreensão dos sentidos não significa apreendermos uma resposta única, coerente, absolutamente definida, completa, mas expressões muitas vezes parciais, prenhes de contradições, muitas vezes não significadas pelo sujeito, mas que nos apresentam indicadores das formas de ser do sujeito, de processos vividos por ele.

Sabemos quão difícil é sua apreensão, ele não se revela facilmente, ele não está na aparência, muitas vezes o próprio sujeito o desconhece, não se apropria da totalidade de suas vivências, não as articula.

Não podemos esquecer que o pensamento, sempre emocionado, não pode ser entendido como algo linear, fácil de ser captado, não é algo pronto, acabado. É interessante quando Vigotski (2001) afirma que o pensamento muitas vezes termina em fracasso, não se converte em palavras. O autor, em A tragédia de Hamlet - o príncipe da Dinamarca, já anunciava sua compreensão sobre a complexidade do humano ao afirmar que, "o que ocorre em cena é apenas parte da projeção e do reflexo de outros acontecimentos que se desenrolam nos bastidores". (Vigotski, 1999, p. 4). Entender nosso sujeito, o professor, implica, portanto, aproximar-se das zonas de sentido, no caso, os sentidos da atividade. Então, como apreendê-los? Que caminho nos conduziria a tal tarefa?

Apresentadas tais categorias centrais, torna-se mais fácil, quase uma decorrência, a compreensão de que objeto e método de investigação estão estreitamente articulados e que se constituem mutuamente. Ao afirmarmos uma determinada concepção de humano e as categorias essenciais de sua organização subjetiva, assim como o objetivo que se apresenta em estudo, somos "empurrados" para a construção de alternativas metodológicas. Nesse sentido, apresentamos uma proposta de análise do discurso.

Como afirma Kosik (2002, p. 20), "a dialética é o pensamento crítico que se propõe a compreender a 'coisa em si' e sistematicamente se pergunta como é possível chegar à compreensão da realidade". Temos que, nesse processo, considerar a dialética objetividade/subjetividade e compreender que a realidade social encontra múltiplas formas de ser configurada pelo sujeito, podendo tal configuração ocorrer sem a desconstrução de velhas concepções e emoções calcadas em preconceitos, visões ideologizadas, fragmentadas etc. Mas, este é nosso rumo.

\section{Procedimentos para análise através dos núcleos de significação}

Antes de entrarmos no tema da análise, consideramos adequada a apresentação de alguns apontamentos sobre a "coleta" de material a ser analisado, isto é, os procedimentos e instrumentos recomendados para uma investigação dentro da abordagem sócio-histórica. 
Neste artigo trabalharemos com entrevistas, entendidas como um instrumento rico que permite acesso aos processos psíquicos que nos interessam, particularmente os sentidos e os significados. Sem a pretensão de ampliar uma discussão sobre este procedimento de coleta, gostaríamos de atentar para algumas características que marcam este instrumento e que, sem dúvida, interferem no seu potencial de captação ou apreensão dos sentidos e significados buscados.

- As entrevistas devem ser consistentes e suficientemente amplas, de modo a evitar inferências desnecessárias ou inadequadas.

- Elas devem ser recorrentes, isto é, a cada entrevista, após uma primeira leitura, o informante deverá ser consultado no sentido de eliminar dúvidas, aprofundar colocações e reflexões e permitir uma quase análise conjunta do processo utilizado pelo sujeito para a produção de sentidos e significados.

- Mesmo considerando que uma boa entrevista pode contemplar material suficiente para uma análise, se houver condições, alguns outros instrumentos podem permitir aprimoramento e refinamento analítico. Para isso, recomenda-se um plano de observação, no processo das entrevistas, tanto para captar indicadores não verbais como para complementar e parear discursos e ações que estão nos objetivos da investigação.

Outros instrumentos úteis e possíveis de utilização são: relatos escritos, narrativas, história de vida, frases incompletas, autoconfrontação, vídeo-gravação e, inclusive, questionários ou desenhos, desde que sejam complementados e aprofundados através de entrevistas.

\section{Leitura flutuante e organização do material}

\section{Os pré-indicadores}

Consideramos que a palavra com significado é a primeira unidade que se destaca. Partimos dela sem a intenção de fazer uma mera análise das construções narrativas, mas com a intenção de fazer uma análise do sujeito. Assim, temos que partir das palavras inseridas no contexto que lhe atribui significado, entendendo aqui como contexto desde a narrativa do sujeito até as condições histórico-sociais que o constitui.

O esforço empreendido é na direção de, num processo construtivointerpretativo, partir do empírico, mas, superá-lo. Os núcleos de significação expressam o movimento de abstração que, sem dúvida, contém o empírico, mas pela sua negação, permitindo o caminho em direção ao concreto. Buscamos, a partir do que foi dito pelo sujeito, entender aquilo que não foi dito: apreender a fala interior do professor, o seu pensamento, o processo (e as contradições presentes nesse processo) de constituição dos sentidos que ele atribui à atividade de docência. 
Sendo assim, nas diversas leituras do material transcrito, destacamos conteúdos das falas do professor que sejam reiterativos, que demonstrem maior carga emocional ou ambivalências. Esses conteúdos são chamados de pré-indicadores e, geralmente, apresentam-se em grande número e irão compor um quadro amplo de possibilidades para a organização dos núcleos. Os pré-indicadores são, portanto, trechos de fala compostos por palavras articuladas que compõem um significado, carregam e expressam a totalidade do sujeito e, portanto, constituem uma unidade de pensamento e linguagem.

Um critério básico para filtrar estes pré-indicadores é verificar sua importância para a compreensão do objetivo da investigação.

\section{Os indicadores e conteúdos temáticos}

Seguindo o processo de análise, o movimento empreendido é de aglutinação dos pré-indicadores, seja pela similaridade, pela complementaridade ou pela contraposição, de modo que nos levem a uma menor diversidade, no caso já dos indicadores. Estes critérios para aglutinação não são necessariamente isolados entre si. Por exemplo, alguns indicadores podem ser complementares pela semelhança do mesmo modo que pela contraposição: um fato identificado como pré-indicador, ao ser aglutinado, pode indicar o caráter impulsionador/motivador para ação em uma determinada condição. Inversamente, o mesmo fato pode funcionar como paralisador da ação em outro momento, mas ambos podem ser indicadores importantes no processo de análise. Um indicador pode ter potências e coloridos diferentes em condições diversas, tais como: fases ou etapas da trajetória de vida, tipos de relações com outros, experiências profissionais, etc.

Recorremos a Kosik (2002, p. 57), quando afirma, "Eis aqui o fundamento de todo conhecimento: a cisão do todo". Porém, o avanço em direção à apreensão da totalidade só se efetivará quando essas partes/ recortes forem integradas novamente ao todo, no movimento histórico de seu processo de constituição. O processo de análise, dessa forma, continua com a construção dos indicadores, que consiste em proceder a um novo movimento de articulação. Entendemos, desse modo, que os indicadores só adquirem algum significado se inseridos e articulados na totalidade dos conteúdos temáticos contidos nas expressões do sujeito. De posse desse conjunto (os indicadores e seus conteúdos), devemos, neste momento, voltar ao material das entrevistas e iniciar uma primeira seleção de seus trechos que ilustram e esclarecem os indicadores.

Este momento já caracteriza uma fase do processo de análise que aponta um início de nuclearização. 


\section{Construção e análise dos núcleos de significação}

\section{A construção dos núcleos de significação}

A partir da releitura do material, considerando a aglutinação resultante (conjunto dos indicadores e seus conteúdos), iniciamos um processo de articulação que resultará na organização dos núcleos de significação através de sua nomeação. Os indicadores são fundamentais para que identifiquemos os conteúdos e sua mútua articulação, de modo a revelarem e objetivarem a essência dos conteúdos expressos pelo sujeito. Nesse processo de organização dos núcleos de significação - que tem como critério a articulação de conteúdos semelhantes, complementares e/ou contraditórios -, é possível verificar as transformações e contradições que ocorrem no processo de construção dos sentidos e dos significados, o que possibilitará uma análise mais consistente que nos permita ir além do aparente e considerar tanto as condições subjetivas quanto as contextuais e históricas.

Os núcleos devem ser construídos de modo a sintetizar as mediações constitutivas do sujeito; mediações essas que constituem o sujeito no seu modo de pensar, sentir e agir.

Os núcleos devem expressar aspectos essenciais do sujeito. Eles devem superar tanto os pré-indicadores como os indicadores. Devem, assim, ser entendidos como um momento superior de abstração, o qual, por meio da articulação dialética das partes - movimento subordinado à teoria -, avança em direção ao concreto pensado, às zonas de sentido.

Assim sendo, o processo de construção dos núcleos de significação já é construtivo-interpretativo, pois é atravessado pela compreensão crítica do pesquisador em relação à realidade.

Espera-se, nesta etapa, um número reduzido de núcleos, de modo que não ocorra uma diluição e um retorno aos indicadores. É neste momento que efetivamente avançamos do empírico para o interpretativo (apesar de todo o procedimento ser, desde o início da entrevista, um processo construtivo/interpretativo). Os núcleos resultantes devem expressar os pontos centrais e fundamentais que tragam implicações para o sujeito, que o envolvam emocionalmente e que revelem as determinações constitutivas do sujeito.

Uma sugestão para a nomeação dos núcleos é extrair da própria fala do informante uma ou mais de suas expressões, de modo a compor uma frase curta que reflita a articulação realizada na elaboração dos núcleos e que explicite o processo e o movimento do sujeito, considerando os objetivos do estudo, ou o próprio pesquisador construir uma frase que contenha as características apontadas.

\section{A análise dos núcleos}

A análise se inicia por um processo intranúcleo avançando para uma articulação internúcleos. Em geral, este procedimento explicitará semelhanças e/ou contradições que vão novamente revelar o movimento 
do sujeito. Tais contradições não necessariamente estão manifestas na aparência do discurso, sendo apreendidas a partir da análise e interpretação do pesquisador. Como nos lembra Lefebvre (1975, p. 21), o método dialético nos possibilita "a captação das transições, dos desenvolvimentos, da ligação interna e necessária das partes do todo". Desse modo, este movimento analítico interpretativo não deve ser restrito à fala do informante, ele deve ser articulado (e aqui se amplia o processo interpretativo do investigador) com o contexto social, político e econômico, permitindo o acesso à compreensão do sujeito na sua totalidade.

Como nos lembra Vigotski (1998), um corpo só se revela no movimento. Assim, só avançaremos na compreensão dos sentidos quando os conteúdos dos núcleos forem articulados tanto dentro do próprio núcleo como entre os núcleos. Nesse momento, alcançamos uma análise interpretativa mais completa e sintetizadora, ou seja, quando os núcleos são integrados no seu movimento, analisados à luz do contexto do discurso em questão, à luz do contexto social histórico, à luz da teoria.

Parece-nos importante insistir que o procedimento adotado visa avançarmos do empírico para o interpretativo. Isto é, a partir da fala exterior caminhamos para um plano mais interiorizado, que estamos denominando de zona de sentidos.

Caminhando na compreensão dos sentidos, relembramos a importância da análise das determinações constitutivas do sujeito, e, para isso, é importante apreendermos as necessidades, de alguma forma, colocadas pelos sujeitos e identificadas a partir dos indicadores. Entendemos que tais necessidades são determinantes/constitutivas dos modos de agir/sentir/pensar dos sujeitos. São elas que, na sua dinamicidade emocional, mobilizam os processos de construção de sentido e, é claro, as atividades do sujeito.

\section{Um exemplo de análise}

Para deixarmos mais claro o processo de análise por nós utilizado, por intermédio dos núcleos de significação, faremos uso, como exemplo, de trechos retirados da análise da dissertação de mestrado de Soares (2006), intitulada Vivência pedagógica: a produção de sentidos na formação de professores em serviço. Tal pesquisa foi realizada no Programa de Estudos Pós-Graduados em Educação: Psicologia da Educação da Pontifícia Universidade Católica de São Paulo (PUC-SP).

Essa pesquisa teve como objetivo analisar os sentidos produzidos por professores acerca da sua formação acadêmica e em serviço.

Para a obtenção das informações (constituídas por relatos verbais), foram realizadas entrevistas, apoiadas nos memoriais produzidos pelos professores. Das três professoras entrevistadas, somente uma foi escolhida como sujeito da pesquisa, sendo que, a título de exemplo, utilizaremos parte da análise realizada.

Partindo do pressuposto de que a análise é construtiva e interpretativa e tem a finalidade de ultrapassar o fenômeno na sua aparência e 
assim atingir novas zonas de inteligibilidade, o procedimento para a organização dos núcleos de significação deu-se da seguinte forma: após a transcrição, foi realizada uma leitura flutuante das entrevistas e, a seguir, um levantamento dos temas/conteúdos que se destacaram na fala de Raquel (nome fictício da informante da pesquisa), sendo que tais temas se revelam/expressam em palavras; dessas palavras, que são sempre significadas em seu contexto, emergem os pré-indicadores, que constituem a realidade sócio-histórica do sujeito.

Apresentamos, abaixo, os pré-indicadores inferidos por Soares (2006), a partir da fala de Raquel. 1) Capacitação; 2) Formação superior; 3) Satisfação; 4) Pedagogia; 5) Professora pesquisadora; 6) Professora reflexiva; 7) Convivência com pessoas diferentes; 8) Conhecimentos prévios; 9) Realidade dos alunos; 10) Cidadania; 11) Vontade de conhecer; 12) Interesse; 13) Planejamento flexível; 14) Inovação da prática pedagógica; 15) Motivação para aprender; 16) Ingresso na universidade; 17) Aperfeiçoamento da prática pedagógica; 18) Formação eficaz; 19) Objetivo dos alunos; 20) Objetivo da professora; 21) Professora flexível; 22) Qualidade dos professores formadores; 23) Atividades pedagógicas; 24) Eficiência; 25) Atividades de pesquisa; 26) Frequência às aulas; 27) Mediação docente; 28) Atividades vivenciais; 29) Teoria e prática; 30) Prática de ensino; 31) Conhecimentos prévios; 32) Formação reflexiva; 33) Leitura; 34) Atividades de pesquisa; 35) Sala de aula; 36) Alunos com dificuldades; 37) Interesse dos alunos; 38) Consciência; 39) Autonomia; 40) Expectativas de aprendizagem; 41) Compromisso com o curso; 42) Oportunidade de trabalhar numa escola privada; 43) Dificuldade para lecionar; 44) Apoio pedagógico; 45) Psicologia da Educação; 46) Métodos de ensino; 47) Reprovação escolar; 48) Concepção de aluno; 49) Ensino e aprendizagem; 50) Concepção acerca do curso; 51) Crescimento pessoal; 52) Crescimento profissional; 53) Dificuldades; 54) Enfrentamento das dificuldades; 55) Estudo em grupo.

Apesar de no momento somente apresentarmos as palavras que denominam/expressam os pré-indicadores, no texto da análise realizada por Soares (2006), são apresentados os trechos do discurso de Raquel onde os pré-indicadores estão contidos/constituídos, por exemplo:

Capacitação: no decorrer dos estudos [dos cursos de capacitação], eu vi que existia muita coisa que eu precisava conhecer, não só na teoria, mas também desenvolver na prática, para melhorar a aprendizagem dos meus alunos, como também a minha própria profissão, o meu desenvolvimento como educadora. [...] Eu via que eu não estava totalmente capacitada para assumir uma sala de aula. Como eu iria desenvolver uma aprendizagem satisfatória nos meus alunos se eu estava precisando dessa [...] aprendizagem para mim mesma?

Este procedimento foi adotado com o objetivo de que os pré-indicadores não fossem descolados do conjunto do discurso, garantindo-se, assim, a compreensão dos significados e, no decorrer da análise, dos sentidos atribuídos por Raquel às palavras denominadas de pré-indicadores. 
Concluída a primeira fase, passou-se para a aglutinação dos préindicadores, ou seja, dos diversos temas revelados na fala de Raquel, de acordo com os critérios de "semelhança", "complementaridade" e "contraposição". Tal procedimento permitiu a inferência e sistematização de alguns indicadores, como os que seguem no Quadro 1.

Este processo de aglutinação de pré-indicadores em indicadores ocorreu com base nos critérios já apresentados. Cada indicador do Quadro 1 traz consigo sentidos e significados que só podem ser compreendidos a partir da leitura e interpretação das palavras de Raquel em seu contexto sócio-historicamente determinado.

Concluída a aglutinação dos pré-indicadores em indicadores, passou-se para a terceira fase, que consistiu na inferência e sistematização dos núcleos de significação, conforme Quadro 2. Para que Soares chegasse a esta fase, procedeu à articulação dos indicadores, considerando os conteúdos temáticos que apresentavam semelhança, tinham aspectos complementares e/ou continham alguma contradição. Além disso, como um critério central para organização dos núcleos, esses indicadores devem, além de expor aspectos importantes e reveladores do sujeito, contribuir para que se atinja o objetivo da pesquisa.

Quadro 1 - Organização dos Indicadores e Pré-Indicadores

(continua)

\begin{tabular}{|c|c|}
\hline Pré-indicadores & Indicadores \\
\hline $\begin{array}{l}\text { 1) Capacitação. } \\
\text { 2) Formação superior. } \\
\text { 3) Satisfação. } \\
\text { 4) Pedagogia. }\end{array}$ & 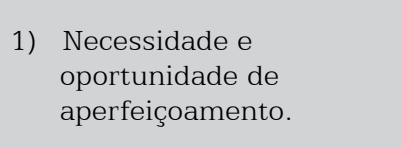 \\
\hline $\begin{array}{l}\text { 5) Professora pesquisadora. } \\
\text { 6) Professora reflexiva. } \\
\text { 7) Convivência com pessoas diferentes. } \\
\text { 8) Conhecimentos prévios. } \\
\text { 9) Realidade dos alunos. } \\
\text { 10) Cidadania. }\end{array}$ & $\begin{array}{l}\text { 2) Uma nova concepção do } \\
\text { papel de professora e } \\
\text { educadora. }\end{array}$ \\
\hline $\begin{array}{l}\text { 11) Vontade de conhecer. } \\
\text { 12) Interesse. } \\
\text { 13) Planejamento flexível. }\end{array}$ & $\begin{array}{l}\text { 3) A construção de } \\
\text { uma nova concepção } \\
\text { pedagógica de aluno, } \\
\text { ensino e aprendizagem. }\end{array}$ \\
\hline $\begin{array}{l}\text { 14) Inovação da prática pedagógica. } \\
\text { 15) Motivação para aprender. }\end{array}$ & $\begin{array}{l}\text { 4) Prática pedagógica e } \\
\text { motivação para aprender. }\end{array}$ \\
\hline $\begin{array}{l}\text { 16) Ingresso na universidade. } \\
\text { 17) Aperfeiçoamento da prática pedagógica. } \\
\text { 18) Formação eficaz. } \\
\text { 19) Objetivo dos alunos. } \\
\text { 20) Objetivo da professora. } \\
\text { 21) Professora flexiva. }\end{array}$ & $\begin{array}{l}\text { 5) A construção de um novo } \\
\text { modo de ser professora. }\end{array}$ \\
\hline $\begin{array}{l}\text { 22) Qualidade dos professores formadores. } \\
\text { 23) Atividades pedagógicas. } \\
\text { 24) Eficiência. } \\
\text { 25) Atividades de pesquisa. } \\
\text { 26) Frequência às aulas. } \\
\text { 27) Mediação docente. }\end{array}$ & $\begin{array}{l}\text { Postura ética, técnica, } \\
\text { estética e política dos } \\
\text { professores formadores. }\end{array}$ \\
\hline
\end{tabular}




\section{Quadro 1 - Organização dos Indicadores e Pré-Indicadores}

\begin{tabular}{|c|c|}
\hline Pré-indicadores & Indicadores \\
\hline $\begin{array}{l}\text { 28) Atividades vivenciais. } \\
\text { 29) Teoria e prática. } \\
\text { 30) Prática de ensino. }\end{array}$ & 7) A relação teoria e prática. \\
\hline $\begin{array}{l}\text { 31) Conhecimentos prévios. } \\
\text { 32) Formação reflexiva. }\end{array}$ & $\begin{array}{l}\text { 8) Os conhecimentos } \\
\text { prévios no processo de } \\
\text { formação do professor. }\end{array}$ \\
\hline $\begin{array}{l}\text { 33) Leitura. } \\
\text { 34) Atividades de pesquisa. } \\
\text { 35) Sala de aula. } \\
\text { 36) Alunos com dificuldades. }\end{array}$ & $\begin{array}{l}\text { 9) A realidade } \\
\text { multifacetada da sala de } \\
\text { aula. }\end{array}$ \\
\hline $\begin{array}{l}\text { 37) Interesse dos alunos. } \\
\text { 38) Consciência. } \\
\text { 39) Autonomia. }\end{array}$ & $\begin{array}{l}\text { 10) A construção da } \\
\text { autonomia pedagógica do } \\
\text { professor-cursista. }\end{array}$ \\
\hline $\begin{array}{l}\text { 40) Expectativas de aprendizagem. } \\
\text { 41) Compromisso com o curso. } \\
\text { 42) Oportunidade de trabalhar numa escola } \\
\text { privada. } \\
\text { 43) Dificuldade para lecionar. } \\
\text { 44) Apoio pedagógico. } \\
\text { 45) Psicologia da Educação. }\end{array}$ & $\begin{array}{l}\text { 11) Apropriação/objetivação } \\
\text { do processo histórico do } \\
\text { ser professora. }\end{array}$ \\
\hline $\begin{array}{l}\text { 46) Métodos de ensino. } \\
\text { 47) Reprovação escolar. } \\
\text { 48) Concepção de aluno. } \\
\text { 49) Ensino e aprendizagem. }\end{array}$ & $\begin{array}{l}\text { 12) A relação professor/aluno } \\
\text { no processo de ensino e } \\
\text { aprendizagem. }\end{array}$ \\
\hline $\begin{array}{l}\text { 50) Concepção acerca do curso. } \\
\text { 51) Crescimento pessoal. } \\
\text { 52) Crescimento profissional. }\end{array}$ & $\begin{array}{l}\text { 13) A formação como } \\
\text { processo de superação } \\
\text { da dicotomia pessoal/ } \\
\text { profissional. }\end{array}$ \\
\hline $\begin{array}{l}\text { 53) Dificuldades. } \\
\text { 54) Enfrentamento das dificuldades. } \\
\text { 55) Estudo em grupo. }\end{array}$ & $\begin{array}{l}\text { 14) Estratégias de } \\
\text { enfrentamento } \\
\text { e superação das } \\
\text { dificuldades. }\end{array}$ \\
\hline
\end{tabular}

Fonte: Soares, 2006. 
Quadro 2 - Organização dos Indicadores e Núcleos de Significação

\begin{tabular}{|c|c|}
\hline Indicadores & Núcleos de significação \\
\hline $\begin{array}{l}\text { 1) Necessidade e oportunidade de } \\
\text { aperfeiçoamento. } \\
\text { 2) Uma nova concepção do papel de } \\
\text { professora e educadora. } \\
\text { 3) A construção de uma nova concepção } \\
\text { pedagógica de aluno, ensino e } \\
\text { aprendizagem. } \\
\text { 4) Prática pedagógica e motivação para } \\
\text { aprender. } \\
\text { 5) A construção de um novo modo de ser } \\
\text { professora. } \\
\text { 7) A relação teoria e prática. } \\
\text { 13) A formação como processo de superação } \\
\text { da dicotomia pessoal/profissional. }\end{array}$ & $\begin{array}{l}\text { 1) A atuação pedagógica } \\
\text { docente como atividade } \\
\text { vital humana. }\end{array}$ \\
\hline $\begin{array}{l}\text { 6) Postura ética, técnica, estética e política } \\
\text { dos professores formadores. } \\
\text { 7) A relação teoria e prática. } \\
\text { 8) Os conhecimentos prévios no processo de } \\
\text { formação do professor. } \\
\text { 9) A realidade multifacetada da sala de aula. }\end{array}$ & $\begin{array}{l}\text { 2) A postura pedagógica } \\
\text { dos professores } \\
\text { formadores. }\end{array}$ \\
\hline $\begin{array}{l}\text { 5) A construção de um novo modo de ser } \\
\text { professora. } \\
\text { 7) A relação teoria e prática. } \\
\text { 9) A realidade multifacetada da sala de aula. } \\
\text { 13) A formação como processo de superação } \\
\text { da dicotomia pessoal/profissional. }\end{array}$ & $\begin{array}{l}\text { 3) A relação teoria e prática } \\
\text { no processo de formação } \\
\text { acadêmica. }\end{array}$ \\
\hline $\begin{array}{l}\text { 2) Uma nova concepção do papel de } \\
\text { professora e educadora. } \\
\text { 3) A construção de uma nova concepção } \\
\text { pedagógica de aluno, ensino e } \\
\text { aprendizagem. } \\
\text { 7) A relação teoria e prática. } \\
\text { 11) Apropriação/objetivação do processo } \\
\text { histórico do ser professora. } \\
\text { 12) A relação professor/aluno no processo de } \\
\text { ensino e aprendizagem. } \\
\text { 13) A formação como processo de superação } \\
\text { da dicotomia pessoal/profissional. }\end{array}$ & $\begin{array}{l}\text { 4) A mediação afetiva } \\
\text { na constituição do ser } \\
\text { professora. }\end{array}$ \\
\hline $\begin{array}{l}\text { 2) Uma nova concepção do papel de } \\
\text { professora e educadora. } \\
\text { 6) Postura ética, técnica, estética e política } \\
\text { dos professores formadores. } \\
\text { 14) Estratégias de enfrentamento e superação } \\
\text { das dificuldades. }\end{array}$ & $\begin{array}{l}\text { 5) A superação das } \\
\text { dificuldades vividas na } \\
\text { formação acadêmica. }\end{array}$ \\
\hline
\end{tabular}

Fonte: Soares, 2006 


\section{Análise dos núcleos de significação}

Articulados os diversos indicadores, inferiram-se e sistematizaram-se os núcleos de significação acima e deu-se continuidade ao processo de aproximação das zonas de sentido que constituem o sujeito da pesquisa com relação ao seu processo formativo no curso de Pedagogia. Para que essa aproximação fosse possível, o autor levou em conta que, "para compreender a fala de alguém, não basta entender suas palavras; é preciso compreender seu pensamento (que é sempre emocionado), é preciso apreender o significado da fala" (Aguiar, 2001, p. 130).

Do ponto de vista procedimental, a análise ocorreu, inicialmente, de forma intranúcleo, ou seja, levando em conta os dados que constituem cada um dos núcleos. Posteriormente, avançou-se para uma análise de internúcleos (Aguiar; Ozella, 2006).

Apresentaremos a seguir, com o intuito de exemplificar a forma de análise proposta, alguns trechos e comentários acerca de um dos núcleos organizados por Soares (2006). Escolhemos o Núcleo 1.

Núcleo 1: atuação pedagógica docente como atividade vital humana

Soares (2006) inicia sua análise afirmando que "é praticamente incontestável o fato de que muitos jovens brasileiros sonham com a oportunidade de ter um curso superior". É justificável, então, o fato de que este desejo também fizesse parte dos sonhos de Raquel. Um curso superior representava para ela, assim como representa para muitos jovens, a oportunidade de poder superar muitos obstáculos vividos nas condições adversas da sociedade. Esse desejo, contudo, não se explica por si só. Para isso, exige-se algo mais complexo, exige-se a compreensão da unidade necessidade/motivo como processo constitutivo do humano (Aguiar, Ozella, 2006).

Ao ressaltar a unidade necessidade/motivo, com base na Psicologia Sócio-Histórica, o autor evidencia a importância da teorização na análise para que se ilumine zonas do real, construindo assim o que denominamos o processo construtivo interpretativo da análise. Outro aspecto importante deste trecho é a compreensão da necessidade de sempre se olhar a realidade singular à luz da totalidade social, ou seja, não se esquecer das determinações históricas e sociais.

Perseguindo a meta de explicar a "gênese social do individual", como nos ensinou Vigotski (2001), Soares aponta que com o ingresso na carreira do magistério, fato que aconteceu um ano após ter concluído o $2^{\circ}$ grau com habilitação em magistério, Raquel passou a configurar de forma mais intensa a necessidade de aperfeiçoamento. Essa necessidade não foi gestada, contudo, apenas pelo fato de dar aula, mas pela participação em grupo de estudo, com colegas professores, e em cursos de capacitação, conforme explicita: "Eu percebi, no decorrer dos meus estudos, nos cursos de capacitação que eu participava com os demais professores, 
supervisores e coordenadores, que eu sentia essa necessidade, que era ter uma formação superior".

Conforme aponta Rey (2003, p. 207), "a ação dos sujeitos implicados em um espaço social compartilha elementos de sentidos e significados gerados dentro desses espaços, os quais passam a ser elementos da subjetividade individual". Dessa forma, Soares destaca que não podemos compreender a subjetividade de Raquel, os novos sentidos por ela produzidos, sem levar em conta os fatos sócio-históricos que a determinam na relação com o mundo, as necessidades e os motivos que configuram o seu modo de ser professora. De acordo com Aguiar e Ozella (2006, p. 8-9), "a possibilidade de realizar uma atividade, que vá na direção da satisfação das necessidades, com certeza modifica o sujeito, criando novas necessidades e novas formas de atividade. [...] Este movimento se define como a configuração das necessidades em motivos".

Desse modo, o autor da pesquisa em questão apreende que "a relação de Raquel com educadores num espaço social específico, ou seja, num espaço de estudo com colegas professores e técnicos pedagógicos, se configura como um processo de determinação do modo pelo qual ela passou a pensar, sentir e agir como professora". Implicada pelo novo contexto, Raquel expressa:

No decorrer dos estudos [dos cursos de capacitação], vi que existia muita coisa que eu precisava conhecer [...] para melhorar a aprendizagem dos meus alunos [e] o meu desenvolvimento como educadora.

Nesse espaço de novas relações, Raquel passa a gestar novas necessidades, ao mesmo tempo que passa a constituir motivos impulsionadores de suas ações.

A vivência de Raquel no curso pode ser compreendida, pela análise feita, como algo que, ao satisfazer suas necessidades, justifica sua dedicação aos estudos. No intuito de evidenciar tal percepção, o autor destaca a seguinte afirmação: "Durante a trajetória do curso, percebi que ele foi melhor do que o que eu imaginava no início. Foi um curso bastante proveitoso. Tanto contribuiu para o meu crescimento pessoal como para o meu crescimento profissional". É importante ressaltar que, de acordo com a perspectiva sócio-histórica, entende-se por necessidade "um estado de carência do indivíduo que leva a sua ativação com vista a sua satisfação, dependendo das suas condições de existência" (Aguiar, Ozella, 2006, p. 8).

Segundo Soares (2006), a relação de Raquel com o curso pode ser compreendida como algo que lhe constitui afetiva e cognitivamente como pessoa una, integral. Dessa forma, ao falar da sua trajetória no curso, Raquel revela, além de afinidade, envolvimento com as atividades acadêmicas. Na sua fala, o curso aparece como algo que atravessou significativamente seu modo subjetivo de pensar, sentir e agir como aluna e professora: "[...] pude ter a oportunidade de melhorar a minha prática pedagógica, me preparar melhor para atuar em sala de aula, e contribuir para que meus alunos pudessem ter uma formação mais eficaz, mais participativa, pudessem aprender mais e melhor". O autor ressalta 
que "a fala de Raquel revela algo mais do que compromisso com o curso, revela compromisso com o seu modo de ser professora, com o seu modo de atuar junto aos seus alunos e, dessa forma, contribuir para que estes tenham uma formação mais eficaz".

Neste momento da análise, evidencia-se a relevância de se focar e desvelar os processos afetivos envolvidos. Com essa intenção, Soares destaca a importância de "compreendemos o compromisso de Raquel com o curso e os alunos como algo atravessado profundamente pelo o que ela sente em relação ao processo pedagógico do ensinar e aprender. A fala de Raquel a revela de modo afetivamente implicada no/pelo processo de sua formação e atuação profissional, ou seja, como aluna e professora".

Teorizando e iluminando a complexa questão da afetividade, o autor traz relevante citação de Leite (2006):

A afetividade constitui-se como um fator de grande importância na determinação da natureza das relações que se estabelecem entre os sujeitos (alunos) e os demais objetos de conhecimento (áreas e conteúdos escolares), bem como na disposição dos alunos diante das atividades propostas e desenvolvidas. É possível, assim, afirmar que a afetividade está presente em todos os momentos ou etapas do trabalho pedagógico desenvolvido pelo professor. (Leite, 2006, p. 24).

Mostrando satisfação em ter concluído seus estudos, Raquel expressa a sua transformação a partir do envolvimento com as atividades acadêmicas do curso:

Antes, eu achava que somente eu tinha objetivo, que era o de repassar os conteúdos. Ser aquele professor rigoroso, detentor do saber; hoje, não! Hoje, eu tento ser uma professora flexiva! Sei que ainda preciso melhorar. Todos nós precisamos sempre melhorar! Mas hoje eu vejo que melhorei bastante.

Continuando sua análise histórica e dialética, Soares afirma que "no curso, Raquel se revela como um sujeito historicamente determinado, ou seja, uma professora em processo de transformação, um sujeito que se apropria do modo de ser a partir da relação com o mundo, o que determina um processo de transformação no seu modo de pensar, sentir e agir ante o espaço de suas relações sociais. Nesse processo histórico de apropriação e transformação do modo de ser mundo, Raquel se objetiva como professora".

O que possibilita o desenvolvimento histórico é justamente o fato de que a apropriação de um objeto (transformando-o em instrumento, pela objetivação da atividade humana nesse objeto, inserindo-o na atividade social) gera, na atividade e na consciência do homem, novas necessidades e novas forças, faculdades e capacidades. (Duarte, 1993, p. 35).

Continuando a análise, o autor aponta que: "ao afirmar que o curso contribuiu significativamente com o processo de sua formação docente, Raquel revela-se cognitiva e afetivamente implicada. No curso, Raquel 
encontrou elementos que a motivaram, que satisfizeram significativamente suas necessidades sociais, singulares, subjetivas. Dessa forma, reconhece que é uma professora em transformação".

Hoje, dentro da escola, eu me vejo como uma professora pesquisadora mais interessada pelo trabalho que faço. Não que antes não me sentisse assim, interessada; mas, a partir do curso, é diferente! Sinto-me uma professora pesquisadora, incentivadora, uma professora mais reflexiva, que contribui não só para que os alunos tornem-se mais participativos, ativos, mas também no seu lado pessoal, de saber conviver com outras pessoas, com pessoas diferentes. Antes eu via que eu tinha que ensinar conteúdos aos alunos. Hoje, vejo que eu tenho um papel mais importante! É um papel que vai além disso, do ensino dos conteúdos. Meu papel é também formar alunos para que eles possam atuar de forma mais consciente no lugar onde moram, que possam ter autonomia própria; autonomia para saber refletir e resolver uma situação-problema do lugar onde moram, assim como no meio da família; ter autonomia com relação à sua própria sala de aula como estudante, como cidadão.

Finalizando a análise deste núcleo, o autor afirma que "Raquel configura o seu modo de ser professora a partir das relações estabelecidas com o mundo. Relações, estas, que são sempre marcadas por elementos que revelam afeto e significados e sentidos. Não é, portanto, apenas na sala de aula, onde atua como professora, que Raquel constitui o seu modo de ser docente, mas na oportunidade de poder estudar e discutir o seu modo de atuar pedagogicamente".

Concluindo nossas considerações sobre a análise realizada por Soares, afirmamos que, ao recorrer a algumas das categorias analíticas e metodológicas da Psicologia Sócio-Histórica, Raquel criou as condições de ultrapassar a simples descrição dos dados, estabelecer relações que até então não haviam sido feitas, detectar a gênese de alguns fatos e se afastar de explicações naturalizantes.

É importante destacar ainda que, para nos aproximarmos de uma apreensão mais global do sujeito, é necessária a articulação de todos os núcleos levantados. Em alguns casos, pela qualidade da informação obtida, a análise pode ficar, num primeiro momento, mais circunscrita a aspectos da história do sujeito, entretanto, ao serem articulados com informações advindas da realidade social e cultural e com os outros núcleos, evidenciam-se outras determinações fundamentais, fazendo, inclusive, com que as informações adquiram outra qualidade. Acreditamos que, neste movimento de articulação dos núcleos entre si - e com as condições sociais, históricas, ideológicas, de classe, gênero, e, sem dúvida, com os conhecimentos cientificamente produzidos sobre a área em questão -, uma nova realidade surge, mais complexa, integrada, reveladora das contradições, movimento este fundamental para a apreensão da constituição dos sentidos.

Temos a clareza, no entanto, da complexidade deste exercício de explicar como são múltiplas as determinações dos fatos. Desse modo, percebemos que, sem dúvida, outros determinantes poderiam ser contemplados nas explicações realizadas, mas que este é um momento do conhecimento atingido. 
Com isso, não estamos afirmando a possibilidade de produzirmos um conhecimento acabado, definitivo, mas sim de alcançarmos uma apreensão maior da rede de determinações constitutiva dos sentidos da atividade. Sabemos que esta não é uma tarefa simples. A subjetividade não se constitui simplesmente pela apropriação das determinações, de modo linear; temos que, neste processo, considerar a dialética objetividade/ subjetividade, mas este é nosso rumo. Acreditamos que o que pode não garantir, mas ser de grande auxílio nessa empreitada, é a clareza e a articulação necessária do método, da teoria e dos objetivos da pesquisa. No entanto, sabemos quão fácil é cometermos o deslize de, neste percurso, sermos ingênuos ou prepotentes, de nos deixarmos enganar pelas falsas aparências ou de acreditarmos na onipotência do pesquisador, do método e/ou da teoria.

\section{Referências bibliográficas}

AGUIAR, Wanda Maria Junqueira. A pesquisa em psicologia sóciohistórica: contribuições para o debate metodológico. In: BOCK, A. M. B.; GONÇALVES, M. G. M.; FURTADO, O. (Orgs.). Psicologia sócio-histórica: uma perspectiva crítica em psicologia. São Paulo: Cortez, 2001.

AGUIAR, Wanda Maria Junqueira; OZELLA, Sérgio. Núcleos de significação como instrumento para a apreensão da constituição dos sentidos. Psicologia Ciência e Profissão, v. 26, n. 2, p. 222-246, 2006.

AGUIAR, Wanda Maria Junqueira et al. Reflexões sobre sentido e significado. In: BOCK, Ana Mercês B.; GONÇALVES, Maria da Graça M. (Orgs.). A dimensão subjetiva da realidade: uma leitura sócio-histórica. São Paulo: Cortez, 2009.

DUARTE, Newton. A individualidade para-si: contribuição a uma teoria histórico-social. Formação do indivíduo. Campinas, SP: Autores Associados, 1993.

HELLER, Agnes. Teoria de los sentimientos. Barcelona: Fontana, 1986. KOSIK, Karel. Dialética do concreto. 7. ed. Rio de Janeiro: Paz e Terra, 2002.

LEFEBVRE, H. Lógica formal e lógica dialética. Rio de Janeiro:

Civilização Brasileira, 1975.

LEITE, Sergio Antônio S. Afetividade e práticas pedagógicas. São Paulo: Casa do Psicólogo, 2006. 
LUKÁCS, George. Ontologia do ser social: os princípios ontológicos fundamentais de Marx. São Paulo: LECH, 1979.

LUKÁCS, George. Estética: categorias básicas de lo estético. Tomo 3. Barcelona: Grijalbo, 1967.

MÉSZÁROS, I. A teoria da alienação em Marx. Trad. Isa Tavares. São Paulo: Boitempo, 2006.

OLIVEIRA, B. A. Dialética do singular-particular-universal. In: ENCONTRO DE PSICOLOGIA SOCIAL E COMUNITÁRIA. Anais do $V$ Encontro... Bauru, SP: Abrapso, 2001. p. 1-24.

REY, Fernando Luis González. Sujeito e subjetividade: uma aproximação histórico-cultural. São Paulo: Thomson, 2003.

REY, Fernando Luis González. La investigación cualitativa en psicologia: rumbos y desafios. São Paulo: Educ, 1999.

SEVERINO, Antônio Joaquim. Educação, sujeito e história. São Paulo: Olho d'Água, 2002.

SMOLKA, A. L. B. Sentido e significação - sobre significação e sentido: uma contribuição à proposta de rede de significações. In: ROSSETTI-FERREIRA, M. C. (Org.). Rede de significações e o estudo do desenvolvimento humano. Porto Alegre: Artmed, 2004.

SOARES, Júlio R. Vivência pedagógica: a produção de sentidos na formação de professores em serviço. 2006. Dissertação (Mestrado em Educação: Psicologia da Educação) - Pontifícia Universidade Católica de São Paulo (PUC-SP), 2006. Orientadora: Wanda Maria Junqueira de Aguiar.

VIGOTSKI, Lev S. Teoría de las emociones: estúdio históricopsicológico. Madrid: Akal, 2004.

VIGOTSKI, Lev S. A construção do pensamento e da linguagem. São Paulo: Martins Fontes, 2001.

VIGOTSKI, Lev S. A formação social da mente: o desenvolvimento dos processos psicológicos superiores. São Paulo: Martins Fontes, 1998.

VIGOTSKI, Lev S. Obras escogidas. v. 1. Madrid: Visor, 1991 a.

VIGOTSKI, Lev S. Obras escogidas. v. 3. Madrid: Visor, 1991b. 
Wanda Maria Junqueira de Aguiar, doutora em Psicologia (Psicologia Social) pela Pontifícia Universidade Católica de São Paulo (PUCSP), é professora do Programa de Educação: Psicologia da Educação da PUCSP e do curso de Psicologia da mesma instituição.

iajunqueira@uol.com.br

Sergio Ozella, doutor em Psicologia (Psicologia Social) pela Pontifícia Universidade Católica de São Paulo (PUCSP), é professor titular da mesma instituição.

allezos@uol.com.br

Recebido em 17 de agosto de 2011.

Aprovado em 7de novembro de 2012. 